\title{
大圈航路に関する一考察
}

\section{A Consideration on Great-circle tracks}

\section{平岩節 (北海道大学水産学部)}

\begin{abstract}
The time required to sail between any two points is dependent on the distance, speed of the ship and the effects of external forces owing to the weather, sea conditions, etc.

Accordingly, to select the most economic and efficient course, the navigator has to form his judgement on the basis of synthetical data founded on the efficiency and the condition of the ship, safety of the course, positions of the two terminals of the course, and season.

In this paper, the writer, relying on assumptions, offered some considerations on the difference of distance between great-circle and rnumb-line, which is an element to be considered in the selection of the most economic course.

\section{1 緒言}

二地点間を航する昜合大圈航路を採れば距離の短縮に伴う時間、燃料、労力等の節減という利 点がある為洽く用いられるととは周知の事実であるか所要時間は距離、船速と外界の条件とによ つて決まるので最も経済的、能率的な航路選定には複雑な諸要因方含まれている。即ち海象、気 象等の外力が船船の運航に与える影響の大小と航行距離の長短とを対比検討の上季節海域に底じ て選定さるべきであるが本稿に於てはその要因の一つである距離関し二点閒の大圈距離と航程 線距離の差違について若干の朲討、考察を試みた。
\end{abstract}

\section{2 二点間の大圈距離と航程線距離の比及び差}

地表面上の二点を夫ぬ $\phi_{1} \lambda_{1} ; \phi_{2} \lambda_{2}$ で表わせば該二点間の大圈距離 $D$ 及び航程線上の距離 $d$ は夫љ $D=\cos ^{-1}\left\{\sin \varphi_{1} \cdot \sin \varphi_{2}+\cos \varphi_{1} \cdot \cos \phi_{2} \cdot \cos \left(\lambda_{1}-\lambda_{2}\right)\right\}$,

$$
d=\frac{\left(\phi_{1}-\boldsymbol{\varphi}_{2}\right) \sqrt{\left(\lambda_{1}-\lambda_{2}\right)^{2}+\left\{\log \tan \left(\frac{\varphi_{1}}{2}+\frac{\pi}{4}\right)-\log \tan \left(\frac{\phi_{2}}{2}+\frac{\pi}{4}\right)\right\}^{2}}}{\log \tan \left(\frac{\varphi_{1}}{2}+\frac{\pi}{4}\right)-\log \tan \left(\frac{\varphi_{2}}{2}+\frac{\pi}{4}\right)}
$$

なる式にて表わされる。此の両者の差違を表示する方法としては差を以てするか此率によるかの 何れかであるが本稿に於ては外力の影響との比較或は全航程に対する短縮表示という意味に於て 主として後者の方法によつた。而して経差 $(D . L)$ 別に短縮率 $\frac{d-D}{D}$ を図示したのが Fig. 1 

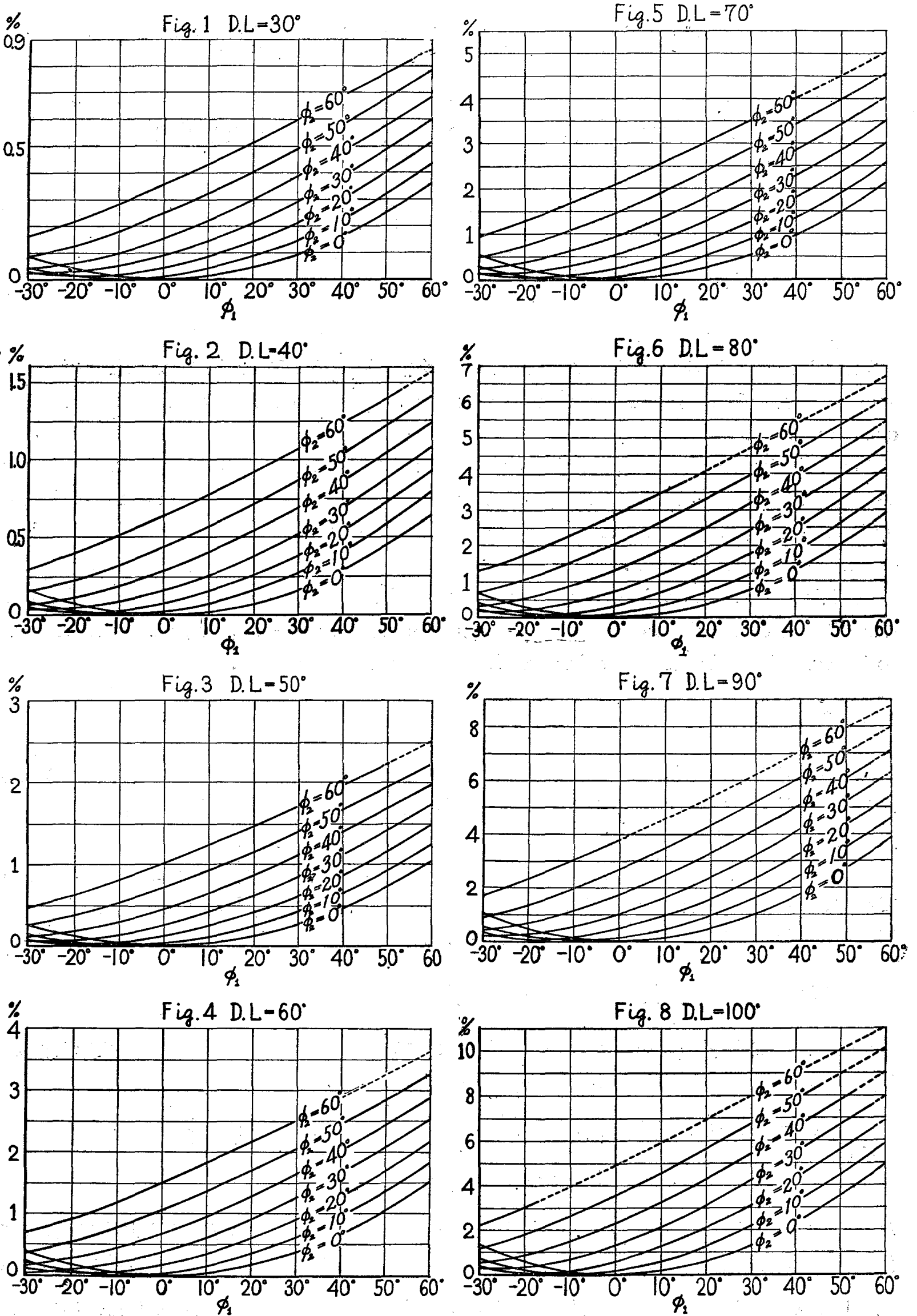
〜Fig. 8 である。図載範囲は両地の経差を $30^{\circ} \sim 100^{\circ}$ 、緯度を $-30^{\circ} \sim 60^{\circ}$ としヌ二点がこの最 高緯度 $\left(60^{\circ}\right)$ 以下に位しても頂点緯度がての限界を越す組合せについては目中点線を以て他と区 別した。その限界は Fig. 9 亿於て $A, V$ の緯度を夫љ $\mathscr{P}_{1}, 60^{\circ}$ とすれば $\angle A P V$

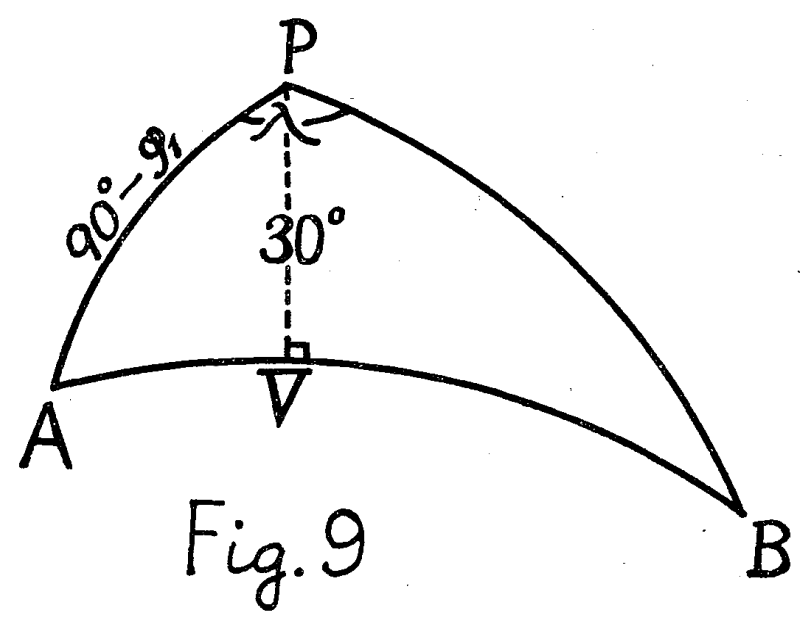

$=\cos ^{-1}\left(\frac{\sqrt{3}}{3} \tan \varphi_{1}\right), \tan \widehat{B P}=\tan V P \cdot \sec B \widehat{P V}$ ょり $\overparen{B P}=\tan ^{-1}$

$\left[\frac{\sqrt{3}}{3} \sec \left\{\lambda-\cos ^{-1}\left(\frac{\sqrt{3}}{3} \tan \varphi_{1}\right)\right\}\right]$ として求められる。

ここに大圈航路といつても正しくその course 上を航することは出来ないので変針間隔の大小に よつて異るも航程線距離との此は四の值より僅汃乍ら小となる。次に是等の図載範围内に於ては 距離比は同一経差について緯度の増大に伴い概ね増加の傾向を示しているが距離差は同範囲内に 於ても極大値を示す点が存在する場合がある。今ての距離差の極值条件を求》てみるに、起程緯 度を $\varphi_{1}$, 着達緯度を $\varphi_{2}$, 経差を $\lambda$, とすれば航程線距離と大圈距離との差 $d-D$ は

$$
\frac{\left(\varphi_{1}-\phi_{2}\right) \sqrt{\lambda^{2}+\left\{\log \tan \left(\frac{\varphi_{1}}{2}+\frac{\pi}{4}\right)-\log \tan \left(\frac{\phi_{2}}{2}+\frac{\pi}{4}\right)\right\}^{2}}}{\log \tan \left(\frac{\phi_{1}}{2}+\frac{\pi}{4}\right)-\log \tan \left(\frac{\varphi_{2}}{2}+\frac{\pi}{4}\right)}
$$

$-\cos ^{-1}\left(\sin \varphi_{1} \sin \varphi_{2}+\cos \varphi_{1} \cos \varphi_{2} \cos \lambda\right)$

にて表わされ、本式に於て $\varphi_{1}, \lambda$ は const.なる故極值条件式は、 $\frac{d(d-D)}{d \phi_{2}}=0$ より $\frac{1}{\left\{M_{1}-\log \tan \left(\frac{\varphi_{2}}{2}+\frac{\pi}{4}\right)\right\}^{2}}$

$$
\cdot\left(\begin{array}{l}
\left\{\log \tan \left(\frac{\varphi_{2}}{2}+\frac{\pi}{4}\right)-M_{1}\right\} \sqrt{\left\{M_{1}-\log \tan \left(\frac{\phi_{2}}{2}+\frac{\pi}{4}\right)\right\}^{2}+\lambda^{2}} \\
+\frac{\lambda^{2} \cdot\left(\phi_{1}-\phi_{2}\right) \sec \varphi_{2}}{\sqrt{\left\{M_{1}-\log \tan \left(\frac{\phi_{2}}{2}+\frac{\pi}{4}\right)\right\}^{2}+\lambda^{2}}}
\end{array}\right.
$$$$
+\frac{\sin \varphi_{1} \cos \varphi_{2}-\cos \varphi_{1} \sin \varphi_{2} \cos \lambda}{\sqrt{1-\left(\sin \varphi_{1} \sin \varphi_{2}+\cos \varphi_{1} \cos \varphi_{2} \cos \lambda\right)^{2}}}=0
$$

但し $M_{1}=\log \tan \left(\frac{\varphi_{1}}{2}+\frac{\pi}{4}\right)$, (1)式に於て $\lambda ， \varphi_{1}$ を与えて $\phi_{2}$ を求めたのが Table 1 である。 但し $\boldsymbol{P}_{2}$ ふ $60^{\circ}$ 以上となる組合せは削除した。 
Table 1

\begin{tabular}{|c|c|c|c|c|c|c|c|c|c|c|}
\hline Lat. from D. long & $10^{\circ}$ & $20^{\circ}$ & $30^{\circ}$ & $40^{\circ}$ & $50^{\circ}$ & $60^{\circ}$ & $70^{\circ}$ & $80^{\circ}$ & $90^{\circ}$ & $100^{\circ}$ \\
\hline $60^{\circ}$ & $8 .{ }^{\circ} 5$ & $9 .{ }^{\circ} 9$ & $12 .^{\circ} 3$ & $15 .^{\circ} 5$ & $19 .^{\circ} 4$ & $23 .{ }^{\circ} 4$ & $27 .{ }^{\circ} 1$ & $30 .^{\circ} 1$ & $32 .{ }^{\circ} 1$ & $33 .{ }^{\circ} 2$ \\
\hline $50^{\circ}$ & & & & & & & & & $59 .{ }^{\circ} 9$ & $54 .{ }^{\circ} 3$ \\
\hline
\end{tabular}

次に起程地と着達地の緯度の符号が異るとき即ち赤道を挾んで南北に存在する場合には距離差 の極小となる点方ゔる。（条件式は(1)に同じ）次に又前記諸葉の図載範囲内に於ては距離此の極 大点は見られないが高緯度の地代於て極大点、反対半球の地に於て極小点が存在する。その条件 を求むるに

航程線距離

$$
\left(\phi_{1}-\phi_{2}\right) \sqrt{\left\{M_{1}-\log \tan \left(\frac{\varphi_{2}}{2}+\frac{\pi}{4}\right)\right\}^{2}+\lambda^{2}}
$$

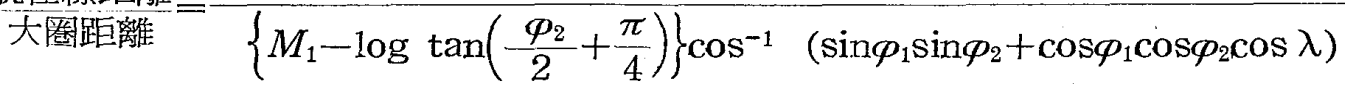

なるにより本式を $\varphi_{2}$ そついて微分し零とおけば

$\cos ^{-1}\left(\sin \varphi_{1} \sin \varphi_{2}+\cos \phi_{1} \cos \varphi_{2} \cos \lambda\right)$

$$
\begin{aligned}
& \left(\frac{-\sqrt{\left\{M_{1}-\log \tan \left(\frac{\varphi_{2}}{2}+\frac{\pi}{4}\right)\right\}^{2}+\lambda^{2}}}{M_{1}-\log \tan \left(\frac{\varphi_{2}}{2}+\frac{\pi}{4}\right)}-\frac{\left(\phi_{1}-\phi_{2}\right) \sec {\varphi_{2}}}{\sqrt{\left.M_{1}-\log \tan \left(\frac{\varphi_{2}}{2}+\frac{\pi}{4}\right)\right\}^{2}+\lambda^{2}}}\right) \\
& +\frac{\left(\varphi_{1}-\phi_{2}\right) \sec \varphi_{2} \sqrt{\left\{M_{1}-\log \tan \left(\frac{\phi_{2}}{2}+\frac{\pi}{4}\right)\right\}^{2}+\lambda^{2}}}{\left\{M_{1}-\log \tan \left(\frac{\varphi_{2}}{2}+\frac{\pi}{4}\right)\right\}^{2}} \\
& \frac{\left(\varphi_{1}-\phi_{2}\right) \sqrt{\left\{M_{1}-\log \tan \left(\frac{\phi_{2}}{2}+\frac{\pi}{4}\right)\right\}^{2}-\lambda^{2}}}{M_{1}-\log \tan \left(\frac{\varphi_{2}}{2}+\frac{\pi}{4}\right)} \cdot \frac{\left(\cos \varphi_{1} \sin \varphi_{2} \cos \lambda-\sin \varphi_{1} \cos \varphi_{2}\right)}{\sqrt{1-\left(\sin \varphi_{1} \sin \varphi_{2}+\cos \varphi_{1} \cos \varphi_{2} \cos \lambda\right)^{2}}} \\
& =0
\end{aligned}
$$

となる。但し $\varphi_{1}, M, \lambda$ は常数にして $M_{1}=\log \tan \left(\frac{\varphi_{1}}{2}+\frac{\pi}{4}\right)$, 而して本式より求められる $\phi_{2}$ は極大が高緯度に、極小点は $\varphi_{1}$ と異符号の地になるので一例を拳げるに止めたい。例えば $\boldsymbol{p}_{1}$ $=30^{\circ} 、 \lambda=100^{\circ}$ なる場合の距離比の極大、極小点は(2)式より夫及 $\varphi_{2}=78 .{ }^{\circ} 6,-27 .{ }^{\circ} 4$ にして 此率は $1.0951 ， 1.0024$ である。又距離差の極小は(1)式より夫及 $\varphi_{2}=75 .{ }^{\circ} 8,-27 .{ }^{\circ} 2$ にしてそ の数值は 359.'33，16.'13 である。本例よりも明らかな如く D. Long が大であつても距離比、 距離差は必ずしも大とは限らなくて極小点附近に於ては僅小であるてとに注目しなければならな い。（距離比の全貌については Fig $1 \sim$ Fig 8 参照)

\section{3 一定の大圈距離に対する距離比}

Lat. $\varphi_{1}$, Long: $\lambda_{1}$ なる点より大圈距離が $D$ (定長) なる点 Lat $\varphi_{2}$. Long $\left(\lambda_{1}+\lambda\right)$ 亿 至る航程線距離を $d$ とすれば $d=\frac{\left(\phi_{1}-\varphi_{2} \sqrt{ }\left(\bar{M}_{1}-M_{2}\right)^{2}+\lambda^{2}\right.}{M_{1}-M_{2}}$ とて表わされる。但し $M_{i}=$ $\log \tan \left(\frac{\varphi_{i}}{2}+\frac{\pi}{4}\right), \lambda=\cos ^{-1}\left(\cos D \sec \varphi_{1} \sec \varphi_{2}-\tan \varphi_{1} \tan \varphi_{2}\right)$ 航程線距離と大圈距離の差 
$d-D$, 或は距離此 $\frac{d}{D}$ に於て $D$ 及び $\varphi_{1}$ は const. なる故何れの極值条件も $\frac{d d}{d \phi_{2}}=0$ を満 足するものである。即ち

$$
\begin{aligned}
& \left(M_{1}-M_{2}\right)\left\{\left(M_{1}-M_{2}\right)^{2}+\lambda^{2}+\left(\varphi_{1}-\phi_{2}\right) \lambda \frac{d \lambda}{d \varphi_{2}}\right\}-\left(\varphi_{1}-\phi_{2}\right) \lambda^{2} \frac{d M_{2}}{d \varphi_{2}}=0 \\
& \text { ここに } \lambda=\cos ^{-1}\left(\cos D \sec \varphi_{1} \sec \varphi_{2}-\tan \varphi_{1} \tan \varphi_{2}\right) \\
& \frac{d \lambda}{d \phi_{2}}=\frac{\sin \varphi_{1}-\cos D \cdot \sin \varphi_{2}}{\cos \varphi_{1} \cos ^{2} \varphi_{2} \sqrt{1-\left(\cos D \sec \varphi_{1} \sec \varphi_{2}-\tan \varphi_{1} \tan \varphi_{2}\right)^{2}}} \\
& \frac{d M_{2}}{d \phi_{2}}=\frac{d}{d \phi_{2}}\left\{\log \tan \left(\frac{\phi_{2}}{2}+\frac{\pi}{4}\right)\right\}=\sec \phi_{2}
\end{aligned}
$$

なる故上記条件式は

$$
\begin{aligned}
& \frac{\left\{M_{-}-\operatorname{lon} \tan \left(\frac{\varphi_{2}}{2}+\frac{\pi}{4}\right)^{2}+\left\{\cos ^{-1}\left(\cos D \sec \varphi_{1} \sec \varphi_{2}-\tan \varphi_{1} \tan \varphi_{2}\right)\right\}^{2}\right.}{\cos ^{-1}\left(\cos D \sec \varphi_{1} \sec \varphi_{2}-\tan \varphi_{1} \tan \varphi_{2}\right)} \\
& \text { - }\left(\varphi_{1}-\varphi_{2}\right) \sec \varphi_{2} \cdot \cos ^{-1}\left(\cos D \sec \varphi_{1} \sec \varphi_{2}-\tan \varphi_{1} \tan \varphi_{2}\right) \\
& M_{1}-\log \tan \left(\frac{\varphi_{2}}{2}+\frac{\pi}{4}\right) \\
& +\frac{\left(\phi_{2}-\phi_{1}\right)\left(\sin \varphi_{1}-\cos D \sin \varphi_{2}\right)}{\cos \varphi_{1} \cos ^{2} \phi_{2} \sqrt{1-\left(\cos D \sec \phi_{1} \sec \phi_{2}-\tan \phi_{1} \tan \varphi_{2}\right)^{2}}}=0
\end{aligned}
$$

となる。乙てで起程緯度 $\boldsymbol{\rho}_{1}$ と一定距離 $D$ を与えて (3)式を満足するものの内航程線距離の最大 となる着详緯度を求めたのが Table 2 である。但し $\varphi_{2}$ の值が $60^{\circ}$ を越す場合は除外した。

\section{4 起程 (or 着達) 緯度を $35^{\circ}$ とした場合の距離比}

二地点間の航程線距離と大圈距離の比或は差は二点の緯度と経差の函数として表わされるから 是等三要素の内一つを常数化すれば閲覽に至便な一葉の図或は表として作製される。今日本を離 れて目的地江向う場合又逆に㾛港する昜合を考え $35^{\circ} \mathrm{N}, 140^{\circ} \mathrm{E}$ なる点を基準にして一航程線距 離一大圈距離 $の$ 等価線を画いたの距離

Fig. 10

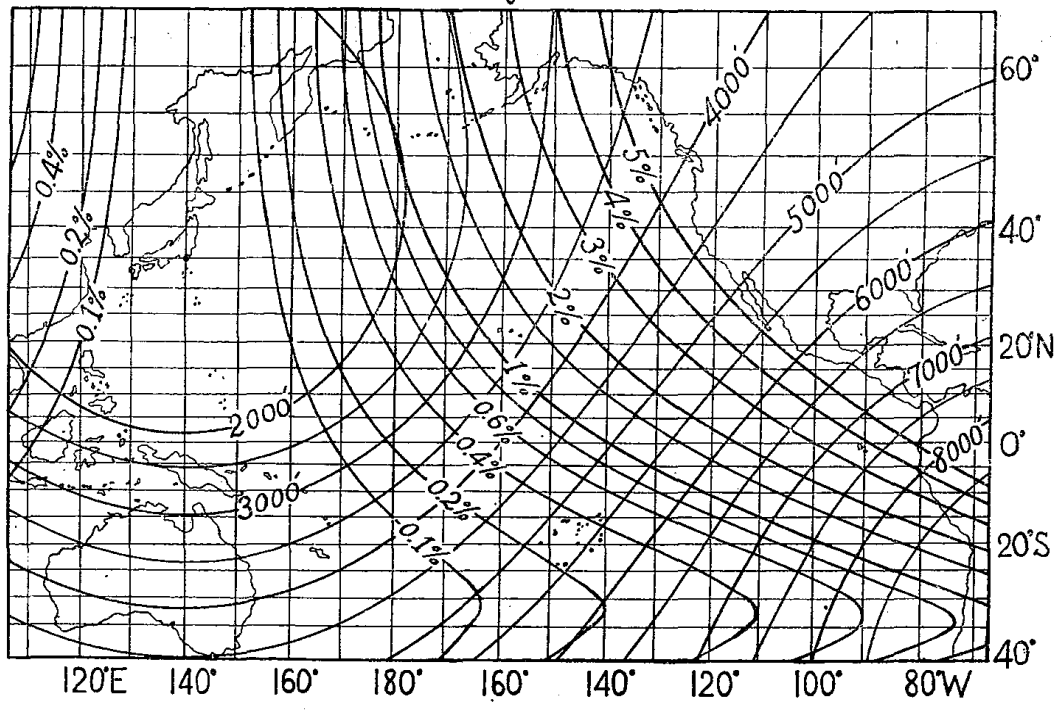


Table 2

\begin{tabular}{|c|c|c|c|c|c|}
\hline $\mathrm{D}$ & $0^{\circ}$ & $10^{\circ}$ & $20^{\circ}$ & $30^{\circ}$ & $40^{\circ}$ \\
\hline $4000^{\prime}$ & $50 .^{\circ} 4$ & $59 .^{\circ} 3$ & & & \\
\hline $3000^{\prime}$ & $36 .^{\circ} 5$ & $43 .^{\circ} 5$ & $52 . .^{\circ} 0$ & & \\
\hline $2000^{\prime}$ & $23 .^{\circ} 9$ & $30 .^{\circ} 2$ & $37 .^{\circ} 7$ & $46^{\circ} 4$ & $56^{\circ} 7$ \\
\hline
\end{tabular}

等洒線をも記しておいたので距離差は雨者の積として容易に求められる。

向同図は Lat $35^{\circ} \mathrm{N}$, Long $140^{\circ} \mathrm{E}$ を基集点にとつて画いたものであるが比等等価線は起程経 度には無関係であるので子午線に沿つて平行移動しても無論同じである。省又南緯 $35^{\circ}$ 基準点 とした場合も本図と同形状であるので起程或は着逆緯度が $35^{\circ}$ である限り洋の東西南北な問わず 適用出来る訳である。

次に前述の如く同一経差について距離此及び距離差の極小となる点が存在する。例えば経差が $90^{\circ}$ なる皆合を考えれば距離比の極小条件は(2)式より $\boldsymbol{\rho}_{2}=-32 .{ }^{\circ} 0$ にして $\frac{\text { 航程線距離 }}{\text { 大圈距離 }}$ $=\frac{6478.70}{6461.70}=1.00263$. 又距離差の極小は(1)式より $\varphi_{2}=-31 .{ }^{\circ} 4$ 亿して航程線距離一大圏距離

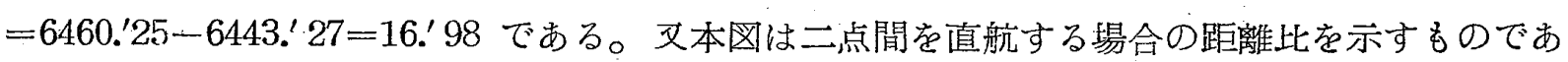
るので連針路の昜合は Fig 1 Ｆig 8 を併用すれば全貌を把握しうる。尚又本図を一瞥して分る 稼に太平洋を抎断する樣な昜合は大圈航路の有利さは判然としているが各種漁船の如く移動経美 が精々 50〜 $60^{\circ}$ 程度の留合は大圈航路を採らなかつた為に生ずる距離の損失率は多くて $1 \%$ 程度 距離差の方では20浬以内と見られるので左程固執する程の有利さは認められない。

\section{5 緒言}

船速低減の原因として考えられているものは海流及潮流。風、波浪等であり是等の外力は船の course の如何飞拘らず勿諭㣫くがその力の相違か船速に及ぼす影響及び持続時間が問題である。 即ち航路選定は航路の安全性と所要時間の短緛に重点が置かるべきであり而して後者を決定する ものは航程と実速力の此率であるので course 别の距離と其の間に受ける海潮流、風浪による減 速量とを勘䓩して適切な計画がなされなければならないが本稿に於て述べた処の距離の短縮率が 海潮流、風浪による減速率の差違との比較に資する処があれば幸甚である。 